\title{
The Impact of Hofstede's National Culture on Usage of Emails Among Academician in Malaysian Public Universities
}

\author{
Anuar Shah Bali Mahomed*1, Michael G. Mcgrath² , Bong Zhi Yuh ${ }^{3}$ \\ ${ }^{1}$ Department Of Management And Marketing, Universiti Putra Malaysia,43400, Malaysia \\ ${ }^{2}$ College Of Business, Victoria University Melbourne, 8001, Australia \\ ${ }^{3}$ Double B, Department Research and Analytic, 70000, Malaysia \\ *Corresponding Author E-Mail: Anuar@Upm.Edu.My
}

\begin{abstract}
This research investigates the impact of Hoftstede's National Culture which mediated by the Technology Acceptance Model (TAM) on usage of emails among academician in Malaysian public universities. Data was collected by using survey questionnaires among 146 academic staff from two public universities in Malaysia. Path analysis was conducted using SmartPLS 2.0 to assess the usage of emails model. Study found that power distance (PD), uncertainty avoidance (UA) and collectivism (C) have negative impact on perceived ease of use (PEOU) of usage of emails. Study further discovered that PD, and C have negative influence on perceived usefulness (PU) of usage of emails. In addition, study found that masculinity (M) has no noteworthy impact on both PEOU and PU of usage of emails. Moreover, long-term orientation (LT) and Indulgence (I) were found to have noteworthy positive relationship with PEOU and PU on usage of emails. On technology acceptance model (TAM), PEOU and PU were found to have noteworthy positive impact on usage of emails (U) while PEOU has a noteworthy positive impact PU of usage of emails. This paper discusses the implications of these findings for future academic research and practice.
\end{abstract}

Keywords: Power Distance (PD); Uncertainty Avoidance (UA); Collectivism (C); Masculinity (M); Long-Term Orientation (LT); indulgence (I); Perceived Ease of Use (PEoU); Perceived Usefulness (PU)

\section{Introduction}

In effort to transform Malaysia towards becoming a developed country by 2020, the government has made the development of Information and Communication Technology (ICT) it's priority under the Vision 2020 plan. Under this mandate the government has undertaken the project of forming the ICT infrastructures with the Multimedia Super Corridor (MSC) in 1995, followed by the implementation of the Malaysian Communications and Multimedia Act in 1999 and crafted ICT as its current main focus under the Eighth Malaysia Plan 2001-2005. A critical goal by the government was to increase the use of ICT in organisations to create communication efficiency, albeit the bigger plan was to actually establish Malaysia as an ICT and multimedia hub, upgrading and increasing communication infrastructures, as well as promoting ecommerce and increasing R\&D (1). In 2005, an allocation of RM 2.2 billion as stated in the Ninth Malaysia Plan was granted for the advancement of ICT for government organisations. This figure is believed to increase by $10 \%$ annually (2). Hence, campaigns and the implementation done by both the government and nongovernmental sectors have brought about advancement of ICT utilisation throughout the nation, as shown by the increment of internet users from $5,008,465$ users $(21.4 \%$ of the total population) in 2000 to $21,090,777$ users (68.6\% of the total population) in 2016 (3). Although the data shows that there is an overall increase in the level of internet usage in Malaysia, recent studies suggest that there is an issue pertaining to the level of usage of emails, frequency (traffic) and email response in Malaysia $(2,4,5)$.
Usage of emails has contributed to performance as well as productivity increase at the workplace (6). For instance, Chui et al. (6) discovered that work productivity has been enhanced by $25-30$ percent through the answering and reading of emails that were related to work. It was also discovered that the use of the internet at work as well as emails, lead towards extensive yearly profit that ranged around $\$ 900$ billion to $\$ 1.3$ trillion throughout these industries which are advanced manufacturing, consumer packaged goods, retail financial services, and professional services that belong in the United States. Yet usage of emails had also disadvantages, where a study done by Eunson (7) shown that the usage of emails in conversations led to an information overload. The problem was found related to the convenience of emails being sent to numerous recipients, as it could be used to share unimportant messages that could distract staff. Jackson et al. (8) was convinced that these emails would be distractions to employees when it came to executing important tasks, due to the time wasted with extra work cause by passing on emails that contain erroneous information, trivial messages, and even incomplete directive, which would need to be referred back to the management (9).

As explained before, many recent study on usage of emails discovered that there is an imbalance of usage of emails particular in Malaysia public and private sectors. For example, a study regarding email responsiveness comprising of the administrative staff found in 24 Malaysian ministries conducted by Mohamad and Hashim (2). A brief mystery email was sent to the staff, requesting some general knowledge about services that the ministry offers, and only $8 \%$ replied, showing that communication through email was not regarded seriously as an official mode for public enquiries (2). 
Through a comparative study conducted between a two public universities, one from Malaysia which is Universiti Teknikal Malaysia Melaka (UTeM) and the other from the United Kingdom, the University of Brighton (UB), Husain et al. (4) notice that administrative staff from the UB acquired around 11 to 50 messages with 20 work-related emails among them. The administrative staff of UTeM on the other hand only received 5-10 emails on average per day, and even receive less than that.

To support this finding, a more recent study by Mahomed (10) among non-academic staff in Malaysia universities discovered that private universities show a significantly larger usage of official emails' in comparison to public universities, supported by a mean rank of 234.41 for private universities as opposed to only 173.44 at 0.05 significance level for public universities.

Some studies indicate that the work culture in private HEIs have promoted better usage of emails. According to Mahomed (10) culture (values and practices) have a noteworthy role in the adoption of innovation and technology which influences the usage of email at universities in Malaysia. In addition, culture determines what is being communicated, and the best method of communication is not necessarily via email. Previous studies in Malaysia indicate that the work culture in private HEIs have promoted better usage of emails (10). Results also show that academician in private universities have higher level of ICT proficiencies when compared to those in public universities (11). In fact, academician in private universities showed higher computer literacy in regards to those from the public universities (11). Previous studies done by Mahomed (10) only concentrated on usage of emails of nonacademic staff in the Malaysian public and private universities and excluded academician in his research. This study will address the problems mentioned by identifying the challenges regarding email adoption in Malaysian offices, concentrating in particular on academician in public and private universities in the country. In addition, in- depth analysis on the patterns of email usage and the role of culture on the adoption of email in both public and private universities is needed in order to recognise, examine and explain the differences in both types of institutions. By considering HEIs as the case study, this research will then focus on one particular type of employee, i.e. the academician in public and private HEIs in Malaysia. They are the academician involved in the areas of teaching, and research and community services duties of which their daily routine involves extensive internal and external documentation and communication. This study believes that the speed in the delivery time of emails and efficiency of academician through the use of emails may give a positive impact on the overall administration performance of the university. This study also will assist the government by contributing relevant knowledge to allow the Malaysian Government to increase and improve the adoption of email communication especially among academician and hence, providing substantial economic benefits.

\section{Literature Review}

Literature highlights the influence of usage of emails in two broad contexts. First, the effectiveness of email is affected by the intention to use it. Second, the acceptance of email is influenced by the cultural context.

\subsection{Technology Acceptance Model (TAM)}

Davis (12) established TAM to describe computer practice behaviour and ICT acceptance in organisations. He identifies Perceived Usefulness (PU) and Perceived Ease of Use (PEOU) as the main determinants of technology acceptance (12-14).

a) Perceived Usefulness (PU)

Perceived Usefulness (PU) "the degree to which a person believes that using a particular system would enhance his or her job performance" (12). 'Usefulness' of a technology is measure by its capability to save time and attain higher competence and precision (15). PU was proven as a noteworthy influencer of email communication adoption in various studies $(5,12,16)$. Recent study by
Mahomed (10) and Mahomed et al. (5) found that the instant a worker highly rated the perceived usefulness of the email, they will also demonstrate higher levels of actual email compliance.

\section{b) Perceived Ease of Use (PEOU)}

Perceived Ease of Use (PEOU) means "the degree to which a person believes that using a particular system would be free of effort and ease giving the idea of freedom from difficulty or great effort" (12). Davis (12) found that PEOU as one of the important factor determining system usage. The more recent study by Mahomed et al. (5) found that there is a noteworthy positive relationship of PEOU in regards to usage of emails seen at Malaysian universities, which implies that technology should be user-friendly and uncomplicated in order for people to use it effortlessly.

This study adopts TAM as its conceptual framework. The reason to adopt TAM rather than other technology acceptance theories is because TAM has superior investigating ability as compared to other technology acceptance theories as suggested by Hong et al. (17). Hong et al. (17) studied the usefulness of three prospective models in exploring a sustained IT consumption. The three models include: Expectation-Confirmation Model in IT Domain (ECMIT), Technology Acceptance Model (TAM), and a hybrid model integrating TAM and ECM-IT (extended ECM-IT). The study found that TAM is the most compatible with data followed by ECM-IT, as well as the extended ECM-IT is the most sparing generic model which is applicable in examining both primary and persistent IT adoption. Moreover, highly noteworthy and valid findings were repeatedly demonstrated while using TAM to analyse email compliance in Western nations $(12,16)$, and Eastern nations (5). Obviously, TAM can be applied to various situations and environments.

\subsection{National Culture}

Ducheneaut (18) claims that technology and financial resources in an organisation alone does not affect the effective use of email communication. In fact, culture and individual actors play equally important roles. Culture plays a role in adopting a new application in an organisation $(5,10)$. Proven by multiple research, culturally associated variables are frequently the major driver for new technologies adoption $(19,20)$. Also, culture decides the tendency of using which medium for messages to be conveyed and received (19).

Culture dimension introduced by Hofstede's has six dimensions, namely power distance (PD), individualism vs. collectivism (IDV), masculinity vs. femininity (MAS), uncertainty avoidance (UA), long-term vs. short-term orientation (LTO) and indulgence vs. restraint (IVR) (21), and their meanings are as below:

\section{a) Power Distance (PD)}

Power distance (PD) is defined as "the extent to which the less powerful members of the institutions and organisations within a country expect and accept that power is distributed unequally" (21). Hofstede (22) states that Malaysia has a very unequal power organisational structure, supported by the highest PD index score (22). The more recent study done in Malaysia by Mahomed (10) suggests that Malaysia has high power distance culture. Mahomed (10) also found that organisations which have higher power distance is likely to have lower likelihood when it comes to accepting the PU and PEOU of usage of emails. Later on, Mahomed et al. (2017)(5) found that PD among non-academic workers at Malaysian public universities power distance only have noteworthy negative impact on perceive ease of use.

\section{b) Uncertainty Avoidance (UA)}

Uncertainty Avoidance (UA) is determined as "the extent to which the members of a culture feel threatened by uncertain or unknown situations" (21). Hofstede et al. (21) showed that Malaysia has a low and weak UA ranked 67 out of 76 countries. Mahomed (2015) also found that organisations with higher uncertainty avoidance culture will more likely have lower levels towards perceived usefulness in regards to usage of emails(23). While Mahomed et al. (5) found that UA among non-academic staff at the Malaysian 
public universities brings a significantly negative impact on perceive usefulness.

\section{c) Collectivism (C)}

According to Hofstede (21), collectivism is "---societies in which people from birth onwards are integrated into strong, cohesive ingroups, which throughout people's lifetimes continue to protect them in exchange for unquestioning loyalty". Malaysia ranks 54 on individualism or 22 on collectivism in (21). This means that Malaysia has high collectivism as compared to individualism. One consequence of this with regards to email (for example) could be that, where IDV is low, usage might be intense among relatively small, close-knit groups but with loose ties only to other groups. Mahomed et al. (5) found that Collectivism among non-academic staff at Malaysian public universities have noteworthy negative influence on perceive usefulness of email.

\section{d) Masculinity}

Hofstede et al. (21) defines masculinity as "when emotional gender roles are clearly distinct: men are supposed to be assertive, tough, and focused on material success, whereas women are supposed to be more modest, tender, and concerned with the quality of life. Femininity is the dominant social feature in a society when emotional gender roles overlap: both men and women are supposed to be modest, tender, and concerned with the quality of life". Malaysia is ranked as between 34-36 in terms of masculinity, amongst 76 countries (21). In other words, in the gender norm of Malaysian society it is never too stratified neither too lenient. Whether there is any connection between MF scores and usage of emails seems an open question and will be tested during this study. However, there is some evidence that men tend to be greater adopters of new information technologies than women (8). While Mahomed et al. (5) found no connection in regards to masculinity with PEOU and PU in Malaysian organisations.

\section{e) Long-Term Orientation (LTO)}

Hofstede et al. (21) defined long-term orientation (LT) as "---the fostering of virtues oriented toward future rewards- in particular perseverance and thrift". While, short-term orientation (ST) is "--the fostering of virtues related to the past and present- in particular, respect for tradition, preservation of 'face', and fulfilling social obligations". Hofstede et al. (21) suggested that Malaysia is ranked 50 amongst 93 countries. Therefore, Malaysian society sits in the middle category, which means they are neither too future orientated nor too past and present orientated. Whether or not this has any implication on the LTO-usage of emails relationship will be another outcome of this study. Mahomed et al. (5) found that long-term orientation was above average among non-academic staff in Malaysian public universities and has a noteworthy positive impact towards perceptions on the ease of use of the e-mail.

\section{f) Indulgence (I)}

This dimension is adopted from the study done by (24). Hofstede et al. (21) explained Indulgence as "---a tendency to allow relatively free gratification of basic and natural human desires related to enjoying life and having fun. In the opposite pole, restraint, reflects a conviction that such gratification needs to be curbed and regulated by strict social norms". Malaysia is ranked between 27th to 29th amongst 93 countries (21). Mahomed (10) found that organisations which have higher indulgence are more likely to have a higher tendency to accept the perceived ease of use of usage of emails. In addition, Mahomed et al. (5) found that indulgence was below average among non-academic staff in Malaysian public universities and have a noteworthy positive influence on perceptions on the ease of use of the e-mail.

Table 1: Hypotheses for Testing Hypothesis

National Culture, Technology Acceptance Model on Usage of emails in Malaysian public universities

H1a: Power distance (PD) significantly influences the perceived usefulness (PU) on usage of emails among academician at universities in Malaysia.

H1b: Uncertainty avoidance (UA) significantly influences the perceived usefulness (PU) on usage of emails among academician at universities in Malaysia. \begin{tabular}{|c|} 
Hypothesis \\
\hline H1c: National Culture - Collectivism $(\mathrm{C})$ significantly influences the per-
\end{tabular} ceived usefulness (PU) on usage of emails among academician at universities in Malaysia.

H1d: National Culture - Masculinity (M) significantly influences the perceived usefulness (PU) on usage of emails among academician at universities in Malaysia

H1e: National Culture - Long-term orientation (LT) significantly influences the perceived usefulness (PU) on email usage among academician at universities in Malaysia.

H1f: National Culture - Indulgence (I) significantly influences the perceived usefulness (PU) on email usage among academician at universities in Malaysia.

H2a: National Culture - Power distance (PD) significantly influences the perceived ease of use (PEOU) on email usage among academician at universities in Malaysia.

H2b: National Culture - Uncertainty avoidance (UA) significantly influences the perceived ease of use (PEOU) on usage of emails among academician at universities in Malaysia.

H2c: National Culture - Collectivism (C) significantly influences the perceived ease of use (PEOU) on usage of emails among academician at universities in Malaysia.

H2d: National Culture - Masculinity (M) significantly influences the perceived ease of use (PEOU) on usage of emails among acad emician at universities in Malaysia.

H2e: National Culture - Long-term orientation (LT) significant$1 y$ influences the perceived ease of use (PEOU) on usage of emails among academician at universities in Malaysia.

H2f: National Culture - Indulgence (I) significantly influences the perceived ease of use (PEOU) on usage of emails among academician at universities in Malaysia.

Technology Acceptance Model on Usage of emails at universities in Malaysia

H3a: Perceived ease of use (PEOU) significantly influences the perceived usefulness (PU) on usage of emails among academician at universities in Malaysia.

H3b: Perceived ease of use (PEOU) significantly influences the usage of emails (U) among academic staff at universities in Malaysia.

H3c: Perceived usefulness (PU) significantly influences the usage o emails (U) among academician at universities in Malaysia.

By conciliating the PEOU and PU together with Hofstede's Culture Model and Technology Acceptance Model, the research model is shown in illustrated in Figure 1:

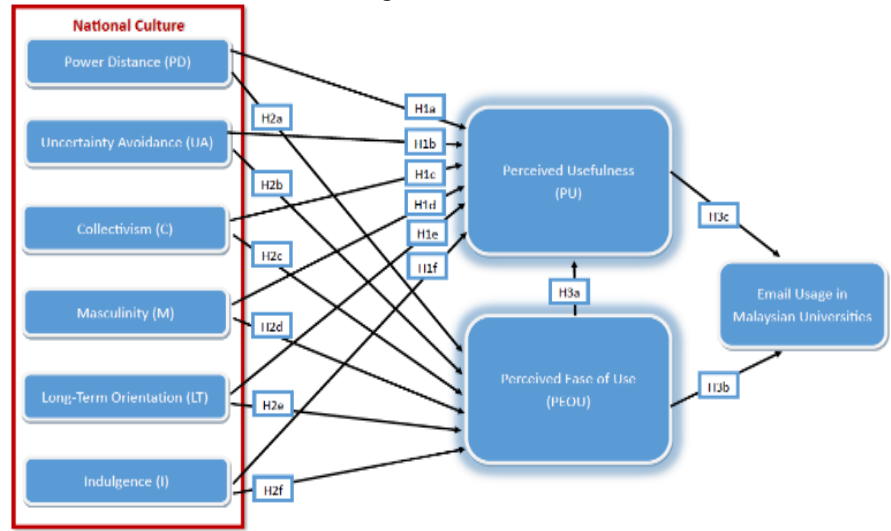

Fig. 1: Research Model

Source: Adopted from Mahomed et al. (2017) using integrated model of Davis (1989) and Hofstede et al. (25)10)

\section{Methodology/Materials}

Around 200 questionnaires have been distributed in two universities, whereby 146 valid questionnaires were taken, concluding with a $73 \%$ percent response rate. The universities were chosen randomly using list of public universities in Malaysia and systematic random sampling was employed to choose the respondent. In addition, the questionnaires have been self-administrated. The questionnaires can be group into three categories, which are demography, national culture and technology acceptance. Demography part measures the basic profile of respondents as well as their actual usage of email. Then, national culture part measures power 
distance (PD), uncertainty avoidance (UA), collectivism (C), masculinity (M), long-term orientation (LT), indulgence (I), while Technology Acceptance Model measures perceived ease of use (PEOU), perceived usefulness (PU) and actual usage (U). In regards to culture measurement, measurement instrument established by Erez and Earley (26), Huang (27), Al-Sukkar (28), and (21)Hofstede et al. (2008) were used. In regards to PEOU and PU, the measurement scale developed through Davis $(1989$, p. 324 \& 340)(12) and Davis et al was used. (12).

When it came to actual usage determination, scales created by Hart and Porter (29), and adopted by Hung (30) and (10) were found compatible with objects that were of actual usage as affirmed through respondents (in demography part), i.e. such as the emails that were sent and received. In order to create a measurement which ranged from 1 (strongly disagree) to 5 (strongly agree) a 5-point Likert scale was adopted. In the meantime, a number of determined response choices were incorporated in regards to the demographic section.

Partial Least Square (PLS) is used in this research to validate the research model and hypothesis testing. The PLS analysis is presented in terms of the measurement model and then the structural model using SmartPLS 2.0. According to Hair et al. (31) PLSSEM is a complete multivariate statistical analysis method that can at the same time investigate relationships among all of the constructs in a research model, including a measurement component and a structural component. Reinartz et al. (32) suggests that a threshold of 100 samples for PLS-SEM analysis, therefore the samples of this study is 146 respondents which above the threshold needed.

\section{Results and Findings}

A culture model and the technology acceptance model has been adopted into this research for the analysis of usage of emails found among academician staff of Malaysian public universities. Data had been gathered through the usage of a survey questionnaires distributed to 146 academician staff at two Malaysian public universities in order to look into the function that culture has on usage of emails found in Malaysian public universities through the incorporation of cultural constructs (PD, UA, C, M, LT and I) and the technology acceptance model (PEOU, PU, U). This research employed the structural equation model (SEM) and PLS approach together in order to attain the research objectives of this study, which are the analysis of the measurement model and structural model. To conduct the SEM analysis, SmartPLS 2.0 was used in the assessment and validation of the measurement model, and also to examine the structural model. For the initial analysis stage, study used SPSS to do the data cleaning in order to identify errors, missing values and to decide which cases to drop. Subsequently, 146 valid samples of academic staff from public university were used for the analysis. The demographic characteristic of respondents was analysed and summarised in Table 2. Results showed that there are slightly more female academic staff in public university (54.1\%). Majority of respondents are Malay and Muslim, accounted for $95.9 \%$ and $97.3 \%$ of respondents. Academic staff in public university came from various age groups, in which those 26-30 years old formed the largest group. The academic staff have minimum education of master level, accounted for $71.2 \%$ while the remaining are holding $\mathrm{PhD}$ degree. Study interviewed those academic staff and found out that majority of Master degree are currently in their PhD pursue. Comparing with Mohamed et al. (5), the different between academic staff and non-academic staff in public university is that majority of academic staff are holding Master degree while majority of non-academic staff are holding Bachelor degree. The position of academic staff in public university are mostly junior lecturer/ tutor. In addition, only $4 \%$ are associate professor and professor.

\begin{tabular}{|c|c|c|}
\hline Characteristic & Frequency & Percentage (\%) \\
\hline \multicolumn{3}{|l|}{ Gender } \\
\hline Male & 67 & 45.9 \\
\hline Female & 79 & 54.1 \\
\hline \multicolumn{3}{|l|}{ Race } \\
\hline Malay & 140 & 95.9 \\
\hline Chinese & 4 & 2.7 \\
\hline Indian & 2 & 1.4 \\
\hline \multicolumn{3}{|l|}{ Religion } \\
\hline Muslim & 142 & 97.3 \\
\hline Buddhist & 2 & 1.4 \\
\hline Hindu & 1 & 0.7 \\
\hline Christian & 1 & 0.7 \\
\hline \multicolumn{3}{|l|}{ Age } \\
\hline $20-25$ years & 8 & 5.5 \\
\hline $26-30$ years & 44 & 30.1 \\
\hline $31-35$ years & 27 & 18.5 \\
\hline $36-40$ years & 21 & 14.4 \\
\hline $41-45$ years & 8 & 5.5 \\
\hline $46-50$ years & 16 & 11 \\
\hline $51-55$ years & 19 & 13 \\
\hline $56-60$ years & 3 & 2.1 \\
\hline \multicolumn{3}{|l|}{ Education } \\
\hline Master Degree & 104 & 71.2 \\
\hline PhD Degree & 42 & 28.8 \\
\hline \multicolumn{3}{|l|}{ Position } \\
\hline Professor & 3 & 2.1 \\
\hline Associate Professor & 3 & 2.1 \\
\hline Senior Lecturer & 23 & 15.8 \\
\hline Lecturer & 19 & 13 \\
\hline Junior Lecturer/ Tutor & 96 & 65.8 \\
\hline
\end{tabular}

\subsection{Measurement Model}

For measurement model's reliability and validity, study examined using composite reliability, convergent validity and the discriminant validity using SmartPLS 2.0 as show in Figure 2.

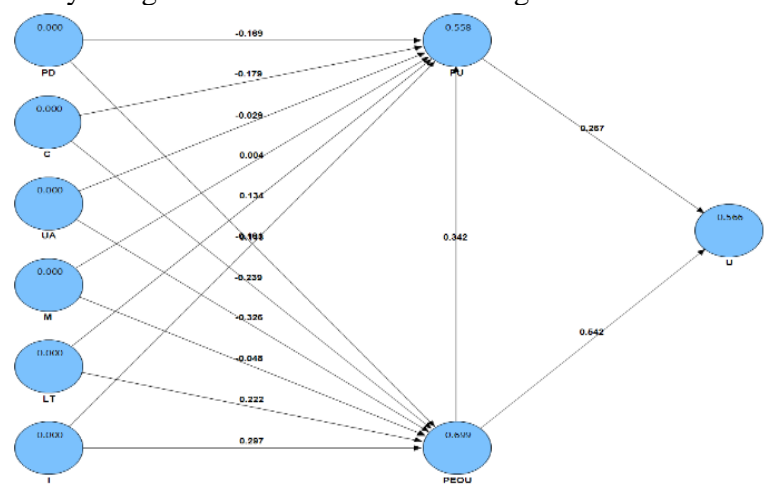

Fig. 2: Model Framework in SmartPLS

\subsection{Reliability and Convergent Validity}

Study followed the guidance as suggested by Hair et al. (31). For reliable measurement, all the composite reliability (CR) need to be higher than the threshold value of 0.7 . Then, convergent validity is determined through the value of factor loading and average variance extracted (AVE). Results in Table 3 showed that CR values were higher than $0.7(0.839-0.935)$, the factor loading for all items were higher than $0.6(0.72-0.97)$, and lastly, the AVE were higher than 0.5 (0.559-0.811). Based on that, the measurement model has satisfactory reliability and convergent validity. Nonetheless, it is important to state that item PD2, C2, UA1, UA5, M1, M5, I3, PU3, PEOU2 were omit from the study due to low factor loading. This finding is indeed, consistent with previous study done by Mahomed et al. (5) in which same items were discarded, except for PD1. 
Table 3: Statistic for Reliability and Convergent Validity

\begin{tabular}{|c|c|c|c|c|}
\hline Constructs & Items & Loading & AVE & CR \\
\hline \multirow[t]{5}{*}{ Usage } & U1 & 0.7388 & 0.5591 & 0.8637 \\
\hline & $\mathrm{U} 2$ & 0.7524 & & \\
\hline & AU_1 & 0.7176 & & \\
\hline & AU_2 & 0.7627 & & \\
\hline & AU_3 & 0.7662 & & \\
\hline \multirow[t]{4}{*}{ Collectivism } & $\mathrm{C} 1$ & 0.8581 & 0.6958 & 0.9013 \\
\hline & $\mathrm{C} 3$ & 0.7859 & & \\
\hline & $\mathrm{C} 4$ & 0.8177 & & \\
\hline & $\mathrm{C} 5$ & 0.8721 & & \\
\hline \multirow[t]{3}{*}{ Indulgence } & $\mathrm{I} 1$ & 0.8996 & 0.7678 & 0.9084 \\
\hline & $\mathrm{I} 2$ & 0.8553 & & \\
\hline & $\mathrm{I} 3$ & 0.8732 & & \\
\hline \multirow[t]{3}{*}{ Long-term Orientation } & LT1 & 0.89 & 0.7053 & 0.8776 \\
\hline & LT2 & 0.8841 & & \\
\hline & LT3 & 0.8324 & & \\
\hline \multirow[t]{3}{*}{ Masculinity } & M2 & 0.8862 & 0.8047 & 0.9251 \\
\hline & M3 & 0.8645 & & \\
\hline & M4 & 0.9389 & & \\
\hline \multirow[t]{4}{*}{ Power Distance } & PD1 & 0.8768 & 0.7705 & 0.9307 \\
\hline & PD3 & 0.885 & & \\
\hline & PD4 & 0.8685 & & \\
\hline & PD5 & 0.888 & & \\
\hline \multirow[t]{4}{*}{ Perceived Ease of Use } & PEOU1 & 0.97 & 0.7836 & 0.9354 \\
\hline & PEOU3 & 0.8943 & & \\
\hline & PEOU4 & 0.8482 & & \\
\hline & PEOU5 & 0.8966 & & \\
\hline \multirow[t]{4}{*}{ Perceived Usefulness } & PU1 & 0.7476 & 0.5665 & 0.8394 \\
\hline & PU2 & 0.7522 & & \\
\hline & PU4 & 0.7733 & & \\
\hline & PU5 & 0.737 & & \\
\hline \multirow[t]{3}{*}{ Uncertainty Avoidance } & UA2 & 0.8818 & 0.8106 & 0.9277 \\
\hline & UA3 & 0.961 & & \\
\hline & UA4 & 0.9127 & & \\
\hline
\end{tabular}

\subsection{Discriminant Validity}

Study conducted discriminant analysis following method by Fornell and Larcker (33) and the findings are as shown in Table 4. Noticed all the square root of AVEs values are higher than the offdiagonal latent correlation values to their corresponding row and column. Thus, the items were able to explain the variances in their own construct more than the other constructs, suggesting that the measurement model demonstrated adequate discriminant validity.

Table 4: Statistics for Discriminant Validity

\begin{tabular}{lccccccccc}
\hline & C & I & LT & M & PD & PEOU & PU & U & UA \\
\hline C & $\mathbf{0 . 8 3 4}$ & & & & & & & & \\
I & 0.548 & $\mathbf{0 . 8 7 6}$ & & & & & & & \\
LT & -0.365 & -0.338 & $\mathbf{0 . 8 4 0}$ & & & & & & \\
M & 0.772 & 0.181 & -0.745 & $\mathbf{0 . 8 9 7}$ & & & & & \\
PD & 0.436 & 0.500 & -0.388 & 0.133 & $\mathbf{0 . 8 7 8}$ & & & & \\
PEOU & -0.546 & -0.559 & 0.574 & -0.172 & -0.567 & $\mathbf{0 . 8 8 5}$ & & & \\
PU & -0.522 & -0.527 & 0.513 & -0.187 & -0.546 & 0.694 & $\mathbf{0 . 7 5 3}$ & & \\
U & -0.435 & -0.426 & 0.478 & -0.144 & -0.429 & 0.727 & 0.643 & $\mathbf{0 . 7 4 8}$ & \\
UA & 0.368 & 0.482 & -0.333 & 0.181 & 0.517 & -0.638 & -0.478 & -0.442 & $\mathbf{0 . 9 0 0}$ \\
\hline
\end{tabular}

Note: diagonals (in bold) represent the squared root of average variance extracted ( $A V E)$ while the other entries represent the correlations between the corresponding constructs

\subsection{Structural Model}

Looking at the national culture model, results showed that collectivism has noteworthy negative influence on perceived ease of use $(\beta=-0.2383, \mathrm{t}=8.827)$ and perceived usefulness $(\beta=-0.1784, \mathrm{t}=$ 4.096), indicating that academic staff with higher collectivism level tend to have lower level of PEOU and PU. Indulgence in contrast was found to has noteworthy positive impact on perceived ease of use $(\beta=0.2978, t=9.235)$ and perceived usefulness $(\beta=$ $0.1181, \mathrm{t}=2.453)$, showing that as indulgence level of public university's academic staff increase, their PEOU and PU will increase as well. Similarly, long-term orientation was found to has noteworthy positive impact on perceived ease of use $(\beta=0.2223, \mathrm{t}$ $=6.076)$ and perceived usefulness $(\beta=0.1375, \mathrm{t}=2.799)$, indicat ing that if the academic staff is long-term oriented, he/she will likely to have high level of PEOU and PU. Furthermore, power distance showed noteworthy negative influence on perceived ease of use $(\beta=-0.1031, t=2.942)$ and perceived usefulness $(\beta=$ $0.1652, t=3.439$ ). Uncertainty avoidance was only found to have noteworthy negative relationship with perceived ease of use $(\beta=$. $0.3251, \mathrm{t}=11.368)$. Looking at technology acceptance model, results revealed that there both perceived ease of use $(\beta=0.5471, \mathrm{t}$ $=12.601)$ and perceived usefulness $(\beta=0.2652, \mathrm{t}=5.096)$ have noteworthy positive influence on usage of email among the public university's academic staff. Latent variables PEOU, PU and U showed R2 value of $0.699,0.558$ and 0.566 , indicating that the national culture model was able to explain $69.9 \%$ of variation in PEOU, 55.8\% of variation in PU and $56.6 \%$ of changes in $U$ of email among the public university's academic staff.

Table 5: Structural Model Analysis

\begin{tabular}{lcccccc}
\hline \multicolumn{1}{c}{ Relationship } & Path & SD & SE & t-value & Hypothesis & $\mathbf{R}^{2}$ \\
\hline Collectivism -> Perceived Ease of Use & -0.2383 & 0.0271 & 0.0271 & $8.827^{*}$ & YES & 0.699 \\
Collectivism -> Perceived Usefulness & -0.1784 & 0.0438 & 0.0438 & $4.096^{*}$ & YES & 0.558 \\
Indulgence -> Perceived Ease of Use & 0.2978 & 0.0321 & 0.0321 & $9.235^{*}$ & YES & \\
Indulgence -> Perceived Usefulness & 0.1181 & 0.0461 & 0.0461 & $2.453^{*}$ & YES & \\
Long-term Orientation -> Perceived Ease of Use & 0.2223 & 0.0366 & 0.0366 & $6.076^{*}$ & YES & \\
Long-term Orientation -> Perceived Usefulness & 0.1375 & 0.0479 & 0.0479 & $2.799^{*}$ & YES & \\
Masculinity -> Perceived Ease of Use & -0.052 & 0.033 & 0.033 & 1.456 & NO & \\
Masculinity -> Perceived Usefulness & 0.0042 & 0.04 & 0.04 & 0.112 & NO & \\
Power Distance -> Perceived Ease of Use & -0.1031 & 0.0342 & 0.0342 & $2.942^{*}$ & YES & \\
Power Distance -> Perceived Usefulness & -0.1652 & 0.0493 & 0.0493 & $3.439^{*}$ & YES & \\
Perceived Ease of Use -> Perceived Usefulness & 0.3385 & 0.0837 & 0.0837 & $4.082^{*}$ & YES & \\
Perceived Ease of Use -> Usage & 0.5471 & 0.043 & 0.043 & $12.601^{*}$ & YES & 0.566 \\
Perceived Usefulness -> Usage & 0.2652 & 0.0524 & 0.0524 & $5.096^{*}$ & YES & \\
Uncertainty Avoidance -> Perceived Ease of Use & -0.3251 & 0.0287 & 0.0287 & $11.368^{*}$ & YES & \\
Uncertainty Avoidance -> Perceived Usefulness & -0.0327 & 0.0492 & 0.0492 & 0.591 & NO & \\
\hline
\end{tabular}

\subsection{Discussions}

The paper set out to investigate the impact of Hofstede's national culture in regards to usage of emails across academician of Malaysian public universities. A total of fifth teen hypotheses relating national culture and Technology Acceptance Model were presented in this study. As shown in table 5, on national culture constructs, the study found that power distance (PD), collectivism (C), long-term orientation (LT) and Indulgence (I) significantly influences the perceived usefulness (PU) and perceived ease of use (PEOU) in regards to the usage of emails among academician at universities in Malaysia. While Uncertainty avoidance (UA) significantly influences only on PEOU on usage of emails among academician at universities in Malaysia. However, Masculinity (M) did not have a significance influences on PEOU and PU on usage of emails among academician at universities in Malaysia. For TAM constructs, this study found all three hypotheses namely PEOU and PU significantly influences the usage of emails (U) across academic workers at universities in Malaysia and Perceived ease of use (PEOU) significantly influences the perceived usefulness (PU) on usage of emails among academician at universities in Malaysia.

This study found that power distance (PD) and collectivism (C) have a negative relationship in regards to PEOU and PU for the usage of emails across academicians at Malaysian universities. As such is in support of material that are about relationship of power distance in regards to the usage of emails. For example, this result matched those observed by Mahomed (10) that also found the negative relationship of power distance (PD) and collectivism (C) on usage of emails among non-academic personnel at universities throughout Malaysia. While Mahomed et al. (5) found power distance (PD) has negative relationship with PEOU among nonacademic workers in Malaysia public institutes. The findings are shown to be consistent with another research conducted by Mutlu and Ergeneli ((34))(35) on usage of emails that established a negative relationship of PD on usage of emails. Therefore, the higher a level of power distance is at a certain university, the tendency for 
an academician in Malaysian public universities to accept the PU and PEOU on usage of emails is lower.

The negative influences of collectivism (C) on usage of emails is in consistent with the finding by Mahomed et al. (5) which found a negative connection between collectivism (C) and PU on usage of emails. Although Al-Hujran (36) discovered collectivism (C) having no noticeable implication on PEOU and PU, evidence shown indicates that it had relevance in regards to both PU and PEOU. As such a higher the level of collectivism (C) at a university, creates a lower tendency for academicians in Malaysian public universities to accept the PU and PEOU in regards to usage of emails. Furthermore, this study also found that uncertainty avoidance (UA) has a noteworthy negative impact on perception on the ease of use (PEOU) on usage of emails. Even though an earlier study done by Saribagloo et al. (37) implies that both TAM constructs most prominently the PEOU and PU indirectly contain a negative relation towards UA when it came to computer adoption at a Tehran University, this research discovered no such relationship between UA on PU on usage of emails.

The relationship connecting long-term orientation (LT) and indulgence (I) with PEOU and PU on usage of emails was also discovered to be positive in this research. Finding were shown to support a previous finding of $(5,10)$ which confirmed a positive relationship between PU on usage of emails at Malaysian universities. However, this study not only found positive relationship between long-term orientation (LT) and indulgence (I) with PU and the relationship is even stronger with long-term orientation (LT) and indulgence (I) has noteworthy positive relationship with both PU and PEOU on usage of emails. This means that the higher the long-term orientation (LT) and indulgence (I) index at a certain university, the higher also would be the tendency of the academician to accept the PU and PEOU of usage of emails. There was no relationship between Masculinity (M) with PEOU and PU on usage of emails found in regards to this research. This result is similar as well as consistent with the previous study done by Mahomed et al. (5) in Malaysian organisations which found no discernible impacts of Masculinity (M) on PEOU and PU.

A positive relationship between PEOU and PU was also found in this study, whereby they demonstrated a noteworthy positive relationship in regards to usage of emails. This supported earlier studies that were done on in regards to the positive relationship of TAM constructs $(5,10,12,38)$. In addition, PEOU having a noteworthy positive relationship with PU. These findings reinforced previous studies on the positive relationship of PEOU with PU $(5,10,12,38)$. Finally, the variance elucidated by the model on PEOU accounted for 69.9 percent, PU was 55.8 percent and the real usage was calculated to about 56.6 percent. This tells that the model was able to explain better the usage of emails among the academic staff of public university in relation to non-academic staff which only have $\mathrm{U}$ explained at $20.4 \%$ as explained by Mahomed et al. (5) . Additionally, Malaysian public university academicians, were seen to have the tendency to consider emails as useful as long as they were easily utilised.

\section{Conclusion}

To sum up, this paper provides evidence towards the role of national culture as well as technological factors regarding the integration of the usage of emails among academician staff in Malaysian public universities. All hypotheses were supported except three hypotheses with two of them related with masculinity construct. On culture aspect, all dimensions found in Hofstede's national culture caused an impact on one variable of perception, either PEOU or PU except masculinity/femininity (M). While on technological aspect, both PEOU and PU have an effect on usage of emails adoption among academician in Malaysian public universities.

Although there are some limitation of the study such as it encompassing only public universities found in Peninsular Malaysia and excluded East Malaysia which is Borneo but this study also delivers substantial commitments in bridging the information gap found in the works and contribute practically towards the improvement of ICT in Malaysian higher education establishments. In regards to theoretical contributions, the research has employed an integrated model of culture and technology acceptance model in order to study the usage of emails among academician in Malaysian public universities. The model for this study also accounted for 56.6 percent of the actual usage of emails which is significantly higher than the previous study done by Mahomed et al. (2017)(5) among non-academic staff in Malaysian public universities at only $20.4 \%$. On practical contribution this study positively provides some useful information on the management level at Malaysian public universities and governmental agencies in order for an increase usage of emails uptake as a platform of communication inside respective organisations subsequently improve overall productivity and organisational competence.

\section{References}

[1] EMP. Eight Malaysia Plan 2001-2005. Kuala Lumpur: Percetakan; 2001.

[2] Mohamad WMW, Hashim NH, editors. The effectiveness of email use by Malaysia government ministries'. International Conference on Business and Economic Research (ICBER 2010) Malaysia, Kuching, Sarawak, Malaysia; 2010.

[3] ILS. Internet Live Stats, Malaysia Internet Users 2016 [Available from: http://www.internetlivestats.com/internet-users/malaysia/.

[4] Husain K, Abdullah AN, Hashim R, Husin N. EFFECT OF E-MAIL USE ON OTHER COMMUNICATION. Journal of Human Capital Development (JHCD). 2009;2(2):87-110.

[5] Mahomed ASB, McGrath MG, Yuh BZ. The Role of National Culture on Email Usage among Non-Academic Staff in Malaysian Public Universities. International Journal of Economics \& Management. 2017;11(1).

[6] Chui M, Manyika J, Bughin J, Dobbs R, Roxburgh C, Sarrazin H, et al. The social economy: Unlocking value and productivity through social technologies. McKinsey Global Institute. 2012;4:35-58.

[7] 7. Eunson B. Communication in the Workplace: John Wiley \& Sons; 2012.

[8] Jackson LA, Ervin KS, Gardner PD, Schmitt N. Gender and the Internet: Women communicating and men searching. Sex roles. 2001;44(5-6):363-79.

[9] Silverstone B. The growth and development of email and its effectiveness as a means of communication. A case study of staff at Pembrokeshire College: MSc Dissertation, University of Glamorgan, UK; 2010.

[10] Mahomed B, Shah A. Examining email usage among non-academic staff in public and private Malaysian Universities: Victoria University; 2015

[11]11. Dawam SRM, Ahmad KA, Jusoff K, Tajuddian T, Elias SJ, Mansor SW. The use of ICT in public and private institutions of higher learning, Malaysia. Computer and Information Science. 2009;2(4):122.

[12]Davis FD. Perceived usefulness, perceived ease of use, and user acceptance of information technology. MIS quarterly. 1989:319-40.

[13] Shah GUD, Bhatti MN, Iftikhar M, Qureshi MI, Zaman K. Implementation of technology acceptance model in e-learning environment in rural and urban areas of Pakistan. World Applied Sciences Journal. 2013;27(11):1495-507.

[14] Jamil F, Ismail K, Mahmood N, Khan NU, Siddique M. Technology incubators and institutional development. Journal Teknologi. 2015; $12: 133-9$

[15] Teo T, Wong SL, Chai CS. A cross-cultural examination of the intention to use technology between Singaporean and Malaysian pre-service teachers: an application of the Technology Acceptance Model (TAM). Journal of Educational Technology \& Society. 2008;11(4):265.

[16] Adams DA, Nelson RR, Todd PA. Perceived usefulness, ease of use, and usage of information technology: A replication. MIS quarterly. 1992:227-47.

[17]Hong S, Thong JY, Tam KY. Understanding continued information technology usage behavior: A comparison of three models in the context of mobile internet. Decision support systems. 2006;42(3):1819-34.

[18]Ducheneaut NB. The social impacts of electronic mail in organizations: a case study of electronic power games using communication genres. Information, Communication \& Society. 2002:5(2):153-88. 
[19] Straub DW. The Effect of Culture on IT Diffusion: E-Mail and FAX in Japan and the US. Information Systems Research. 1994;5(1):2347.

[20] Al-Gahtani SS, Hubona GS, Wang J. Information technology (IT) in Saudi Arabia: Culture and the acceptance and use of IT. Information \& Management. 2007;44(8):681-91.

[21] Hofstede G, Hofstede GJ, Minkov M, Vinken H. Values survey module 2008 manual. Maastricht: Institute for Research on Intercultural Cooperation. 2008.

[22] Hofstede G. Management in a multicultural society. Malaysian management review. 1991;26(1):3-12.

[23]Zaman K, Qureshi M, Bhatti M. The impact of culture and gender on leadership behavior: Higher education and management. Management Science Letters. 2011;1(4):531-40.

[24] Minkov M. What makes us different and similar: a new interpretation of the world values and other cross-cultural data: na; 2007.

[25] Hofstede G, Hofstede GJ, Minkov M. Cultures and organizations software for the mind. Maidenhead: McGraw-Hill Professional; 2010.

[26]Erez M, Earley PC. Comparative analysis of goal-setting strategies across cultures. Journal of applied psychology. 1987;72(4):658.

[27]HUANG L. The impact of cultural values on email acceptance: Evidence from the PRC. 2003.

[28]Al-Sukkar AS. The application of information systems in the Jordanian banking sector: a study of the acceptance of the internet. 2005.

[29] Hart M, Porter G. The impact of cognitive and other factors on the perceived usefulness of OLAP. Journal of Computer Information Systems. 2004;45(1):47-56.

[30]Hung VQ. Applying Technology Acceptance Model in Evaluating the Usage of MISA Accounting Software at SMEs-Nam Dinh Province, Vietnam. 樹德科技大學資訊管理系碩士班學位論文. 2011:1-102.

[31]3Hair J, Black W, Babin B, Anderson R. Multivariate data analysis: A global perspective: Pearson Prentice Hall. USA; 2010.

[32] 3Reinartz W, Haenlein M, Henseler J. An empirical comparison of the efficacy of covariance-based and variance-based SEM International Journal of research in Marketing. 2009;26(4):332-44.

[33] Fornell C, Larcker DF. Structural equation models with unobservable variables and measurement error: Algebra and statistics. Journal of marketing research. 1981:382-8.

[34] Mutlu S, Ergeneli A. Electronic mail acceptance evaluation by entended technology acceptance model and moderation effects of espoused national cultural values beween subjective norm and usage intention. Intellectual economics. 2012;6(2):7-28.

[35] Mutlu S, Ergeneli A. Electronic mail acceptance evaluation by extended technology acceptance model and moderation effects of espoused national cultural values between subjective norm and usage intention. Intelektine Ekonomika. 2012;6(2).

[36] Alhujran O. Determinants of e-government services adoption in developing countries: a field survey and a case study $[\mathrm{PhD}]$ : University of Wollongong, Australia; 2009.

[37]Amani-Saribagloo J, Gholamali-Lavasani M. وجشناد رد ي نا The relationship between cultural values and individual variables with computer use among university students. Journal of Behavioral Sciences. 2011;5(1):1-10.

[38] Ramayah T. The role of voluntariness in distance education students usage of a course website. TOJET: The Turkish Online Journal of Educational Technology. 2010;9(3). 